\title{
EDITORIAL
}

\section{Increased dose of echinocandins for invasive fungal infections: bonanza for the patient or the pharmaceutical industry?}

\author{
Bone Marrow Transplantation (2007) 39, 129-131. \\ doi:10.1038/sj.bmt.1705563
}

Invasive fungal infections continue to plague allogeneic stem cell recipients despite aggressive prophylactic and empiric anti-fungal strategies. Regardless of our best efforts, mortality exceeds $50 \%$ in patients infected with aspergillus and other filamentous molds. ${ }^{1}$ As the number of older patients undergoing transplantation increases and the transplant techniques involve long delays in immune reconstitution, life-threatening fungal diseases and other opportunistic processes are likely to prevail. Polyenes (amphotericin B or its lipid form), azoles (fluconazole, itraconazole) and pyrimidines (5-fluorocytosine) have long been available as anti-fungals; nephrotoxicity of the polyene class and numerous drug interactions associated with azoles have hampered their liberal use. Echinocandins, a recently introduced class of anti-fungal, are remarkably well tolerated, and have an excellent safety profile with minimal drug interactions.

Some comparative data of the three echinocandins are shown in the Table 1 . These drugs, at varied doses, show excellent efficacy in esophageal and systemic candidiasis. Doses recommended easily achieve plasma levels above $1 \mu \mathrm{g} / \mathrm{ml}$, a target selected to exceed the minimal inhibitory concentration (MIC) at which $90 \%$ of clinically relevant candidal species are inhibited throughout therapy. A loading dose is not recommended for micafungin, whereas the plasma levels for caspofungin were noted to fall below the target levels for the first 2 days of therapy when given at $50 \mathrm{mg} /$ day without a loading dose. ${ }^{2}$ Preliminary data show that micafungin at 100 or $150 \mathrm{mg} /$ day has efficacy comparable to caspofungin ( $70 \mathrm{mg}$ followed by $50 \mathrm{mg} /$ day) in invasive candidiasis. ${ }^{3}$ Interestingly, clinical success with anidulafungin was superior to that seen with fluconazole against invasive candidiasis. ${ }^{4}$ Whether the echinocandin's rapid cidal activity contributed to its overall superiority over the azole remains speculative. Echinocandins, at the currently used doses, appear to perform optimally against candida. Against aspergillus, however, these drugs do not exhibit the same level of activity. They kill the growing hyphal tips, but are inactive against the mycelial mass. Available data on the activity of the echinocandins against invasive aspergillosis are limited. At 'standard' doses, success rate of caspofungin as salvage therapy is $40-45 \%$, whereas micafungin, as primary therapy, is reported to have $50 \%$ efficacy (six of 12 patients) when given alone and $29 \%$ efficacy (five of 17 patients) in combination with other drugs. ${ }^{5,6}$ As these drugs are known to have concentrationdependent activity, would higher than 'standard' doses have improved efficacy? Also importantly, would higher doses be as safe as the 'standard' doses?

In Phase I studies, caspofungin (single dose up to $210 \mathrm{mg}$, and multiple doses up to $100 \mathrm{mg} /$ day) has been well tolerated. Preliminary data in 96 patients suggest no dosedependent toxicity across different doses ranging from 35 to $100 \mathrm{mg}$ /day of caspofungin; no difference in efficacy was noted between 50 and $70 \mathrm{mg}$ /day regimens in esophageal candidiasis and invasive aspergillosis. ${ }^{7}$ In animal models, when caspofungin was given every other day, trough levels were difficult to achieve and breakthough infections were noted. Clinical trial is underway examining caspofungin at doses of $70 \mathrm{mg}$ load followed by 50,100 and $150 \mathrm{mg}$ /day for invasive aspergillosis. Another trial examining 50 vs $150 \mathrm{mg} /$ day of caspofungin for invasive candidiasis has enrolled over 50 patients; no serious adverse events were noted (Nicholas Kartsonis, MD, personal communication, Merck \& Co., Inc.). Micafungin was administered at

Table 1 Echinocandins: some comparative data

\begin{tabular}{|c|c|c|c|}
\hline & Caspofungin & Micafungin & Anidulafungin \\
\hline (A) Indications & $\begin{array}{l}\text { esophageal candidiasis (EC), } \\
\text { systemic candidiasis, } \\
\text { febrile neutropenia (empiric therapy), } \\
\text { invasive aspergillosis (salvage therapy) }\end{array}$ & $\begin{array}{l}\text { esophageal candidiasis }(\mathrm{EC}) \text {, } \\
\text { prophylaxis of candidiasis } \\
\text { (pre-engraftment } \\
\text { in stem cell transplant) }\end{array}$ & $\begin{array}{l}\text { esophageal candidiasis (EC), } \\
\text { systemic candidiasis (SC) }\end{array}$ \\
\hline \multicolumn{4}{|c|}{ 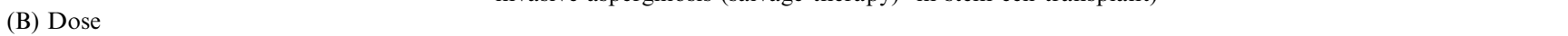 } \\
\hline Initial & $70 \mathrm{mg}$ & No loading dose & $\begin{array}{l}100 \mathrm{mg} / \text { day (EC) } \\
200 \mathrm{mg} / \text { day (SC) }\end{array}$ \\
\hline Maintenance & $50 \mathrm{mg} /$ day & $\begin{array}{l}150 \mathrm{mg} / \text { day (EC) } \\
50 \mathrm{mg} / \text { day (for prophylaxis) }\end{array}$ & $\begin{array}{l}50 \mathrm{mg} / \text { day (EC) } \\
100 \mathrm{mg} / \text { day (SC) }\end{array}$ \\
\hline (C) Higher doses found safe (package insert) & $\begin{array}{l}100 \mathrm{mg} / \text { day } \times 21 \text { days }(15 \text { subjects }) \\
70 \mathrm{mg} \text { day (limited data) }\end{array}$ & $8 \mathrm{mg} / \mathrm{kg} /$ day (up to $900 \mathrm{mg} /$ day) & $\begin{array}{l}260 \mathrm{mg} \\
\text { followed by } 130 \mathrm{mg} / \mathrm{day}\end{array}$ \\
\hline
\end{tabular}


$3-8 \mathrm{mg} / \mathrm{kg} /$ day for a median of 18 days in 36 stem cell recipients; no patient had a grade 3 or grade 4 adverse event considered secondary to the drug. ${ }^{8}$ Based on the properties of concentration-dependent killing activity and post antifungal effect, an alternating day regimen of micafungin at a high dose of $300 \mathrm{mg}$ was compared with $150 \mathrm{mg} /$ day and IV caspofungin at $50 \mathrm{mg}$ /day for the treatment of esophageal candidiasis. ${ }^{9}$ Efficacy rates were similar and importantly, serious adverse events and discontinuation rates were equally low for all three groups, thus providing proof-ofprinciple that alternate day administration of echinocandin is a viable option.

Poor outcomes of invasive aspergillosis, particularly in stem cell recipients have led to investigations of combination of two or more drugs. In vitro and animal model data suggest additive or synergistic activity when an echinocandin is combined with a polyene or azole. ${ }^{10,11}$ Of note, antagonism was noted when polyene/azole combination was used in a neutropenic rabbit model of invasive aspergillosis. ${ }^{12}$ Retrospective clinical studies show conflicting data with echinocandin/azole combination. ${ }^{13,14}$ In this issue, Safdar et al. retrospectively evaluated the safety/ efficacy of caspofungin at a high dose $(100 \mathrm{mg} /$ day $)$ vs standard dose $(50 \mathrm{mg} /$ day) in combination with other drugs for invasive fungal infections (mostly invasive aspergillosis). ${ }^{15}$ Keeping with previous observations, the investigators found no serious adverse reactions with the high dose. Liver and renal functions were similar in the high- and standard-dose groups. Although the efficacy data were difficult to interpret owing to many confounding factors in this relatively small study, the safety of high-dose caspofungin was demonstrated. Whether the combination therapy is superior to monotherapy for invasive aspergillosis needs a prospective evaluation and until then, routine use of a combination of two or more drugs against this infection must be discouraged.

It is worth emphasizing that echinocandins have a limited spectrum of activity. They are not active against clinically relevant pathogens including cryptococcus, trichosporon, rhodotorula and blastoschizomyces among the non-candidal yeasts, and fusarium, zygomyces and scedosporium among the filamentous molds. For non-albicans candida, higher than usual concentrations of echinocandin are required to inhibit Candida parapsilosis, C. rugosa and C. guilliermondii. Although active in vitro, clinical efficacy of the echinocandins against endemic fungi (histoplasma, blastomyces, cocccidioides) has not been demonstrated.

Echinocandins are a worthy addition to our anti-fungal arsenal. Given their excellent efficacy, higher than standard doses of echinocandins for treatment of most cases of invasive candidiasis are not warranted. For primary therapy of invasive aspergillosis, more prospective data are needed to demonstrate the use of echinocandins as monotherapy or in combination with other drugs. Clinical relevance of the in vitro observation of paradoxical negative effect of the echinocandins, as mentioned by Safdar et al., is of some concern. ${ }^{16}$ Lastly, but importantly, the improved safety profile of the recently available anti-fungal drugs has greatly increased the 'abuse potential' for these drugs. In cancer/transplant wards, these drugs are increasingly used in empiric, prophylactic and pre-emptive settings without much evidence-based data. At our institution (Karmanos Cancer Institute/Harper University Hospital), the antifungal (mostly echinocandins and voriconazole) acquistion expense has more than doubled during 2004-2005. Restrained and judicious use of the anti-fungals is critical to avoid 'econo toxicity'.

PH Chandrasekar Division of Infectious Diseases, Wayne State University School of Medicine, Karmanos Cancer Institute/Harper University Hospital, Detroit, MI, USA E-mail: pchandrasekar@med.wayne.edu

\section{References}

1 Herbrecht R, Denning DW, Patterson TF, Bennett JE, Greene RE, Oestmann JW et al. Voriconazole vs Amphotericin B for the primary treatment of invasive aspergillosis. $N$ Engl $J$ Med 2002; 347: 408-415.

2 Stone JA, Holland SD, Wickersham PJ, Sterrett A, Schwarz M, Bonfiglio C et al. Single- and multiple-dose pharmacokinetics of caspofungin in healthy man. Antimicrob Agents Chemother 2002; 46: 739-745.

3 Betts RF, Rotstein C, Talwar D, Nucci M, Dewaele J, Arnold L et al. Micafungin vs caspofungin in the treatment of candidimia/invasive candidiasis. 46th Interscience Conference on Antimicrobial Agents and Chemotherapy, San Francisco, California, 2006 (Late Breaker Session).

4 Reboli A, Rotstein C, Pappas P, Schranz J, Krause D, Walsh T. Anidulafungin vs fluconazole for treatment of candidemia and invasive candidiasis. 45th Interscience Conference on Antimicrobial Agent and Chemotherapy, Washington, DC, 2005 (Abstract \#M-719).

5 Kartsonis NA, Saah AJ, Joy Lipka C, Taylor AF, Sable CA. Salvage therapy with caspofungin for invasive aspergillosis: results from the caspofungin compassionate use study. J Infect 2005; 50: 196-205.

6 Denning DW, Marr KA, Lau WM, Facklam DP, Ratanatharathorn V, Becker C et al. Micafungin (FK463) alone or in combination with other systemic antifungal agents for the treatment of acute invasive aspergillosis. J Infect 2006; 53: $337-349$.

7 Kartsonis N, Teppler H, Ngai A, Bourque M, White M, Williams-Diaz A et al. Efficacy and safety of higher doses of caspofungin. Trends in Medical Mycology. Berlin, Germany, 2005 (Abstract \#P-027).

8 Sirohi B, Powles RL, Chopra R, Russell N, Byrne JL, Prentice $\mathrm{HG}$ et al. A study to determine the safety profile and maximum tolerated dose of micafungin (FK463) in patients undergoing hematopoietic stem cell transplantation. Bone Marrow Transplant 2006; 38: 47-51.

9 Buell D, Koranda L, Drake T, Fisco C. Alternate drug dosing of micafungin in the treatment of esophageal candidiasis. 45th Interscience Conference on Antimicrobial Agents and Chemotherapy, Washington, DC, 2005 (Abstract \#M-719).

10 Perea S, Gonzalez G, Fothergill AW, Kirkpatrick WR, Rinaldi MG, Patterson $\mathrm{TF}$ et al. In vitro interaction of caspofungin acetate with voriconazole agains clinical isolates of Aspergillus sp. Antimicrob Agents Chemother 2002; 46: 3039-3041.

11 Petraitis V, Petraitiene R, Sarafandi AA, Kelaher AM, Lyman CA, Casler HE et al. Combination therapy in treatment of experimental pulmonary aspergillosis: synergistic interaction between an antifungal azole and an echinocanchin. J Infect Dis 2003; 187: 1834-1843. 
12 Meletiadis J, Petraitis V, Petraitiene R, Lin P, Stergiopoulou T, Kelaher AM et al. Triazole-polyene antagonism in experimental pulmonary aspergillosis: in vitro and in vivo correlation. J Infect Dis 2006; 194: 1008-1018.

13 Marr KA, Boeckh M, Carter RA, Kim HW, Corey L. Combination antifungal therapy for invasive aspergillosis. Clin Infect Dis 2004; 39: 797-802.

14 Kubin CJ, Lukose T, Logan A, Sheth N, Sobieszczyk ME, Ramos L et al. Impact of primary combination therapy on outcomes in invasive aspergillosis. 46th Interscience Conference on Antimicrobial Agents and Chemotherapy, San Francisco, California, 2006 (Abstract \#M-899).

15 Safdar A, Rodriguez G, Rolston KVI, O'Brien S, Khouri IF, Shpall EJ et al. High-dose Caspofungin combination antifungal therapy in patients with hematologic malignancies and hematopoietic stem cell transplantation. Bone Marrow Transplant 2007; 39: 157-164.

16 Stevens DA, Espiritu M, Parmar R. Paradoxical effect of caspofungin: reduced activity against Candida albicans at high drug concentration. Antimicrob Agents Chemother 2004; 48: 3407-3411. 